\title{
Online Discussions in Computer Science Courses: How to Make Them an Effective Learning Tool
}

\author{
Stan Kurkovsky, Bhagyavati, Wayne Summers, Christopher Whitehead \\ Department of Computer Science \\ Columbus State University \\ Columbus, GA, USA \\ \{Kurkovsky_Stan, Bhagyavati, Summers_Wayne, Whitehead_Christopher\}@colstate.edu
}

\begin{abstract}
This paper discusses the experience of using asynchronous online discussions obtained by a group of faculty teaching graduate computer science courses online. We also discuss a number of advantages of using asynchronous discussions and how they can enrich the learning experience of students. This is followed by a collection of our practices in course management when online discussions are used. The paper is concluded by a case study describing how online discussions were used in a Data Warehousing course offered to graduate students online.
\end{abstract}

Index Terms - Computer Science education, online courses, asynchronous discussions.

\section{INTRODUCTION}

$\mathrm{D}$ epartment of Computer Science at Columbus State University (CSU) (Columbus, GA, USA) offers a number of undergraduate and graduate degrees, which include a master's degree in applied computer science. In addition to the traditional classroom teaching environment, our students have an opportunity to obtain this degree entirely online. Instructors in these courses do not mandate face-to-face meetings and students can obtain their degree without stepping foot on our campus. Adapting to the online instructional delivery mode requires significantly more time and effort from both faculty and students, at least at the outset. In addition, face-to-face contact time and talk time are replaced by typing time and uploading/downloading time. However, online courses offer many advantages, some of which we will discuss in this paper.

All authors of this paper are members of the graduate faculty at the CSU Computer Science department and all have had experience in teaching online graduate computer science courses [4]. Additionally, all of us use online discussions as a part of or as a complement to the classroom interaction in some of our traditional face-to-face courses [3]. We all post our assignments, exams, and lectures online. This paper focuses on using asynchronous discussions as a tool to enhance the student's experience in graduate computer science courses offered online. Here we will address how the online discussion topics should be selected in order to maximize student participation and learning. We will present our views on different styles of teaching and conducting online discussions, as well as potential impact of the instruction style on the student experience and their success in achieving their expected learning outcomes.

\section{THE NEED FOR ONLINE INTERACTION}

Although the objective of this paper is not to prove that asynchronous discussions are a versatile and necessary component of online courses [7,9], we will briefly highlight some important points of this topic. The objective of any instructor involved in online course delivery is to make the students' experience at least as good as it is in a traditional face-to-face setting [6]. One obvious component that is plentiful in the traditional environment, but must be reintroduced in the online mode, is a diversity of different modes of communication between the instructor and students and among the students themselves. Synchronous or asynchronous online discussions could be used to replenish the lack of interpersonal communication in the online setting. These tools can be used for many purposes from creating a spontaneous debate to facilitating collaborative work of a small group of students on a course project; from clarifying course concepts to answering student questions before an exam.

Synchronous discussions occur at the same time for all participants, and most of the time they are implemented using chat rooms or video conferencing solutions. While synchronous discussions may be a perfect solution for timecritical decision making, they sometimes do not satisfy the goals of online education. The survey of students enrolled in the online master's program in applied computer science at CSU shows that the vast majority of students take online courses because of the convenience. Typically, our graduate students already have full-time or part-time jobs in the IT industry and it would be difficult for all of them to coordinate their schedules and participate in a synchronous discussion at the same time. This is why in this paper we focus our attention on asynchronous discussions, which are best implemented using threaded discussion boards or newsgroups.

\section{ReAching All StUdents}

The mantra that teaching online is "as good as" teaching face-to-face has changed. Teaching online must be better than teaching face-to-face. One tool that can help realize this goal is asynchronous online discussions. If utilized to their full potential, online discussions can also help address 
several major problems inherent to the discussions conducted in a traditional face-to-face classroom environment.

The first problem is that in a traditional classroom, there are always "silent" students who prefer not to participate in any class discussions or student-to-student interactions. Most of the time, these students are simply too shy or, possibly, think that their opinions do not matter too much. There are also the passive learners who prefer reading a textbook to speaking out in class, out of shyness or fear of speaking in public. These issues can be addressed in the online environment. In most cases, students who are too shy can overcome their shyness in the online environment because of their perception that no one can see them while they are participating online. Student identity, however, will be known because discussion posts are typically not anonymous; however, since online students have taken more time to type a thoughtful response, they may be less shy in exposing their opinions in a public forum.

The second problem is that, in traditional discussions conducted in a face-to-face class, there is always the pressure of time [5]. Students must think and act sufficiently rapidly to demonstrate their knowledge to the instructor and their peers before the class is over. Therefore, students have to compete with one another for time to speak. This not only prevents shy students from participating but it also hinders those students who prefer to take time to provide a thorough response to the posed questions. In the online environment, there is no competition for time in threaded discussions. Students can take a reasonably long period time to thoroughly prepare their answers. Since online students typically take more time than their face-to-face counterparts to "speak" out, their responses will be more thoughtful and better prepared; hence, even shy and fearful students will participate because they do not feel pressure to provide a pertinent response extemporaneously.

Another related problem is that in the traditional environment the topic of a discussion may quickly and easily veer off the initial course. In such a situation, some students still might want to come back to the earlier moments in the discussions and voice their opinion. In an online asynchronous discussion, there is no problem with revisiting messages posted earlier. In the online environment, several threads of a discussion can coexist and be visible and open for further expansion. Revisiting earlier threads also enables students to study the responses to their original postings and clarify them further with ad-hoc groups of fellow classmates.

When we teach a traditional class, it is often difficult to involve all of the students in the discussions. It may be hard to reach a particular student sitting in the back. Often students feel intimidated when asked to respond to a question in a face-to-face environment. In the experience of the authors of this paper, we rarely see this in an online discussion. Every student wants to participate and be "heard." We have found online discussions to be a powerful learning tool for all the students in our classes.

However, given the inherent advantages of threaded discussions, one might still ask a question - how do we ensure that all students actively and productively participate in the discussion? The answer lies in the instructional style and the requirements of each course, which must be clearly communicated by the instructor to the students. Issues of online course management are also important because of the specifics that the online environment imposes on all participants of the course. Assigning a grade to online discussions will not only motivate all the students but also offer thoughtful and pertinent responses. A grade and a deadline for awarding credit toward the grade go a long way in ensuring the quality and timeliness of the online postings.

\section{TEACHING APPROACHES}

In this section, we describe the collective experience of the authors of this paper in teaching our online graduate computer science courses. While some of us post discussion topics that require textbook reading and significant research, others post topics that lead to debates and opinionated statements from students. Each of these approaches has been tested during at least two semesters of teaching graduate computer science courses online.

\section{A. Grading Discussions and Posting Deadlines}

Online discussions must be graded in order to encourage all students to post their thoughts. If the discussions are not for credit, not all students will post messages to the discussion threads. Just as in a traditional classroom, there will always be some "silent" students. Discussion topics can be posted weekly and each student can be expected to post at least two responses within the week. This format has been effective because it ensures that students log in at least once a week and participate, akin to attending a traditional lecture and participating in a classroom.

In order for an online course to be effective, the discussion components must provide the opportunity for every student to participate in posting their opinions. Sometimes it may be necessary to accommodate students with slightly different backgrounds by providing them with more flexibility in selecting the discussion questions to answer. One of the ways to achieve that is to allow the students to select one of several posed questions to reply to each week and then later respond to a classmate's discussion stemmed from a different question on topic.

\section{B. Style of Discussion Questions}

Discussion topics may differ in style and content from one week to the other. The topics usually require a thorough reading of the textbook and varying degrees of independent research on the part of the student. Some topics may lend themselves to heated debates and arguments because the posts are strongly opinionated, while others may have straightforward answers and are not argumentative.

As a rule of thumb, students should not be able to answer the posed questions by simply looking up solutions in a book or on the Web. Students are expected to spend considerable time and thought in formulating answers to the questions. By selecting provocative questions, all students should be motivated to take part in the class discussions. 
Discussion questions must be open-ended and posed in a way to require students to have a thorough understanding of the corresponding textbook material. Also, most questions should build upon the previous academic, industrial, or business experience of the students. At the same time, these discussion questions must provoke a free-flowing discussion along the lines of the given topic.

\section{Addressing Different Learning Styles}

Effective online teaching and learning must support students in the active involvement in their own learning process. One way of achieving this goal is to address as many learning modalities as possible within the online environment and to provide as many opportunities as possible for students to become involved. To accomplish this in an online computer science course, one could provide weekly lessons that include five or more discussion questions, and reading, programming, and research assignments.

As part of the weekly discussions, the instructor can assist students in their learning process by posting four types of questions:

1) Questions highlighting the most important aspects of a particular topic or section of a text require a mix of straightforward and factual type responses, as well as responses that involve deeper, cognitive thinking and emotional awareness.

2) Students are required to complete weekly programming assignments and to post images of their solutions. In addition, students must comment on their "trials, tribulations, and insights" in completing the assignments.

3) Students are required to locate Internet resources that expand on the current week's material. As part of this type of question, students are required to summarize the information provided by these resources. This requires students to review alternative points of view, hopefully from other professionals in the industry and academic world, and to discover current and upcoming changes to the fast-paced world of computers and technology.

4) If the course involves a final project, questions are interspersed throughout the course to elicit project milestones, ranging from the initial concept to a rough draft for other students and the instructor to review and provide feedback.

\section{Quantitative Measures}

In order to maintain student involvement on a weekly or other periodic basis, some instructors require students to post messages with a certain minimal word count (e.g. a 150 words). This assists students in actively participating in the course and in reviewing alternative points of view from the student level. The instructor reviews every message that is posted and comments where he or she thinks a student has gone astray, or where more discussion is needed. Instructor involvement is important from the students' perspective because it provides a sense of worth, both for the material and for the students' learning of that material [1].

In order to stimulate their timely participation in discussions, students may be required to post a certain minimal number of posts per discussion. For example, in discussions conducted on the weekly basis, the students can be asked to post at least two messages per each discussion first as a response to the original discussion question and the second as a critique to a message of another student. To ensure the timeliness of the responses, deadlines can be established for each message. Students should always be reminded that it is not the quantity, but the quality of the discussion that matters. However, such quantitative measures help guarantee that all students participate in the discussion actively and participate on time. It is worthwhile to mention that the vast majority of students post more messages than the required minimum because they get engaged in the ongoing discussions.

\section{E. Discussion Participants’ Responsibilities}

In the course syllabus, the instructor may also list both student responsibilities and the responsibilities of the instructor, part of which covers the asynchronous online discussions. In conjunction with these responsibilities, the instructor should provide periodic feedback (e.g. weekly) to the students with guidance on areas that are being performed satisfactorily and better, as well as areas for improvement, including encouraging students to participate more in the discussions if necessary. This weekly feedback promotes instructor-student communication, which also supports active involvement in the course.

\section{F. Long and Short Courses}

Online discussions are an integral part of the student experience, which can become as rich as a regular face-toface classroom experience. Our past experience shows that discussion-centric online courses work best when they are offered during shorter terms, such as in summer. Students do not have enough time to get bored and typically can achieve more in such faster-paced courses. As usual, in these courses online discussions must be accompanied by a variety of traditional assessment and learning tools, such as research and programming assignments, tests and projects. In these short and fast-paced courses, online discussions work best when they are offered on a weekly basis. Our experience indicates that in longer courses lasting an entire semester, it is best to offer discussions in two-week cycles requiring students to revisit previous posts and concentrate on debating with each other the issues raised in the discussion questions.

\section{G. Student Teamwork and Discussions}

Involving students in a productive teamwork must be an integral part of the student experience in their academic studies. This is especially true for graduate programs in computer science and related disciplines. Asynchronous discussions can also be effectively used as a tool to provide students with an opportunity to gain more experience in working within a team. All students in the class can be divided into teams consisting of two to four students. Instead of participating in the discussions individually, student teams will make collective posts to the course discussion boards. Team members will also have a chance to collaborate within the team to work out their collective answers. This work can be conducted using private 
discussion boards or, depending on team members' preferences, using instant messaging tools, chat, telephone conference calls, or face-to-face team meetings. If the instructor chooses to evaluate each student's performance within the team, students should be required to keep transcripts of their meetings and make them available to the instructor. For team projects, the instructor may also ask students to complete individual assessments of their team member's contributions. This ensures that individual team members are held accountable for their contributions to the team effort.

\section{CASE STUdy}

In this section we present a case study demonstrating an active use of online asynchronous discussions. This Data Warehousing course had been offered online during several 7-week summer sessions as an elective in our master's program in applied computer science.

The objective of this course is to introduce students to modern data warehousing technology and to study different aspects of building and maintaining a complete data warehousing solution in a corporate environment. Prior to taking this course, the students are expected to have a thorough background in database systems. As we noted earlier, a large number of our graduate students are already working in the IT field, so this course made a special emphasis to capitalize on their prior experience. However, we also have a large number of traditional students who went on to earn a graduate degree directly after obtaining a bachelor's degree in computer science or a related field. Therefore, this course was designed with both student groups in mind.

TABLE I. DisCussion Questions OfFERED IN A DATA WAREHOUSING COURSE

\begin{tabular}{|c|c|c|}
\hline Week & For students with industrial experience & For students without industrial experience \\
\hline 1 & $\begin{array}{l}\text { How could your company benefit from data warehousing technology? } \\
\text { What kind of data could be gathered and entered into your company's } \\
\text { data warehouse? Provide a detailed answer so that those unfamiliar } \\
\text { with your company could understand all necessary details. }\end{array}$ & $\begin{array}{l}\text { Columbus State University is analyzing possible benefits of creating } \\
\text { and using a data warehousing solution. Suggest what kind of data could } \\
\text { be entered into such a data warehouse. Explain how CSU would benefit } \\
\text { from using this solution. }\end{array}$ \\
\hline 2 & $\begin{array}{l}\text { Last week you discussed how your company could benefit from } \\
\text { applying a data warehousing solution. Identify the steps that your } \\
\text { company would need to undertake to analyze and implement a data } \\
\text { warehousing solution. Provide details relevant to your company's } \\
\text { business. }\end{array}$ & $\begin{array}{l}\text { Last week you discussed how Columbus State University (CSU) could } \\
\text { benefit from applying a data warehousing solution. Identify the steps } \\
\text { that CSU would need to undertake to analyze and implement a data } \\
\text { warehousing solution. Provide details relevant to a typical higher } \\
\text { education business. }\end{array}$ \\
\hline 3 & $\begin{array}{l}\text { Consider all transformations that data must undergo before being } \\
\text { transferred from an OLTP or any other source database into a data } \\
\text { warehouse. Describe all necessary data transformation steps with } \\
\text { regard to your company's business aspects and its data warehousing } \\
\text { solution. Please be specific and provide enough detail and examples } \\
\text { illustrating how your company's business area may impose certain } \\
\text { specific requirements to data transfer and transformation. }\end{array}$ & $\begin{array}{l}\text { Consider all transformations that data must undergo before being } \\
\text { transferred from CSU operational databases into a data warehouse. Do } \\
\text { not focus on the Banner system as some of the participants of this } \\
\text { discussion may not be very familiar with it. Describe all necessary data } \\
\text { transformation steps with regard to a typical higher education business } \\
\text { and the type of data typically collected in university databases. Please } \\
\text { be specific and provide enough detail and examples illustrating how } \\
\text { this type of business (higher education) may impose certain specific } \\
\text { requirements to data transfer and transformation. }\end{array}$ \\
\hline 4 & $\begin{array}{l}\text { Survey the Web or any printed publications for recent articles and } \\
\text { white papers on replication. Compare your findings to replication } \\
\text { types and physical replication models presented in your textbook. To } \\
\text { answer this question, discuss replication issues relevant to your } \\
\text { company's business. Suggest which replication type and physical } \\
\text { replication model will be the best for the data warehousing solution of } \\
\text { your company and explain why. }\end{array}$ & $\begin{array}{l}\text { Survey the Web or any printed publications for recent articles and white } \\
\text { papers on replication. Compare your findings to replication types and } \\
\text { physical replication models presented in your textbook. To answer this } \\
\text { question, discuss replication issues relevant to a typical higher } \\
\text { education business. Suggest which replication type and physical } \\
\text { replication model will be the best for the CSU data warehousing } \\
\text { solution and explain why. }\end{array}$ \\
\hline 5 & $\begin{array}{l}\text { Propose a multidimensional cube structure for your OLAP solution. } \\
\text { List all dimensions with their respective hierarchies. Substantiate your } \\
\text { design and illustrate the necessity of having these proposed } \\
\text { dimensions and their respective hierarchical structure by providing } \\
\text { specific query samples reflecting the nature of your company's } \\
\text { business. }\end{array}$ & $\begin{array}{l}\text { Propose a multidimensional cube structure for your OLAP solution. } \\
\text { List all dimensions with their respective hierarchies. Substantiate your } \\
\text { design and illustrate the necessity of having these proposed dimensions } \\
\text { and their respective hierarchical structure by providing specific query } \\
\text { samples reflecting the nature of higher education business (such as } \\
\text { CSU). }\end{array}$ \\
\hline 6 & $\begin{array}{l}\text { Describe how data mining techniques can be integrated into the data } \\
\text { warehousing solution of your company. What types of data patterns or } \\
\text { trends could be mined from your data warehouse and the original } \\
\text { OLTP system? }\end{array}$ & $\begin{array}{l}\text { Describe how data mining techniques can be integrated into the CSU } \\
\text { data warehousing solution. What types of data patterns or trends could } \\
\text { be mined from CSU data warehouse and the database system that serves } \\
\text { as a source for CSU data warehouse? }\end{array}$ \\
\hline 7 & $\begin{array}{l}\text { As your company evolves, there may be a need to change certain } \\
\text { dimensional attributes in its data warehousing solution. Suggest three } \\
\text { different examples of such changing attributes, solution for which } \\
\text { would fall into one of these categories (one example per category): a) } \\
\text { overwriting the dimension record; b) writing another dimension } \\
\text { record; and c) values in the dimension record. For each example, } \\
\text { explain why you choose this particular solution. }\end{array}$ & $\begin{array}{l}\text { As CSU evolves and grows, there may be a need to change certain } \\
\text { dimensional attributes in its data warehousing solution. Suggest three } \\
\text { different examples of such changing attributes, solution for which } \\
\text { would fall into one of these categories (one example per category): a) } \\
\text { overwriting the dimension record; b) writing another dimension record; } \\
\text { and c) values in the dimension record. For each example, explain why } \\
\text { you choose this particular solution. }\end{array}$ \\
\hline
\end{tabular}

Online discussions accounted for $20 \%$ of the course grade while the rest of it was distributed as follows: tests $-40 \%$, assignments $-20 \%$, and project $-20 \%$. Such a proportion of the discussion weight within the course grade guaranteed 
that the student participation provided a tangible but not a very significant impact on the final grade: the students know that it is important to participate in the discussions, but they are not a single major component of their course grade.

In this course, online threaded discussions were organized as follows. Every week the instructor posts a discussion question. As shown in Table I, each question comes in two versions - for students with and without industrial experience. Each week, students must post a certain minimum number of messages: a reply to the original discussion question and several replies to other students' posts, thereby engaging in discussions with each other. The course syllabus clearly explains that the stated minimums of messages and their deadlines are needed only to guarantee the timely and active participation of all students in the class. While points can be taken off for missing the deadlines or for an insufficiently active participation, points are awarded for the content of the messages - based on how well the students answer the posed questions and on the value that they bring to the overall discussion.

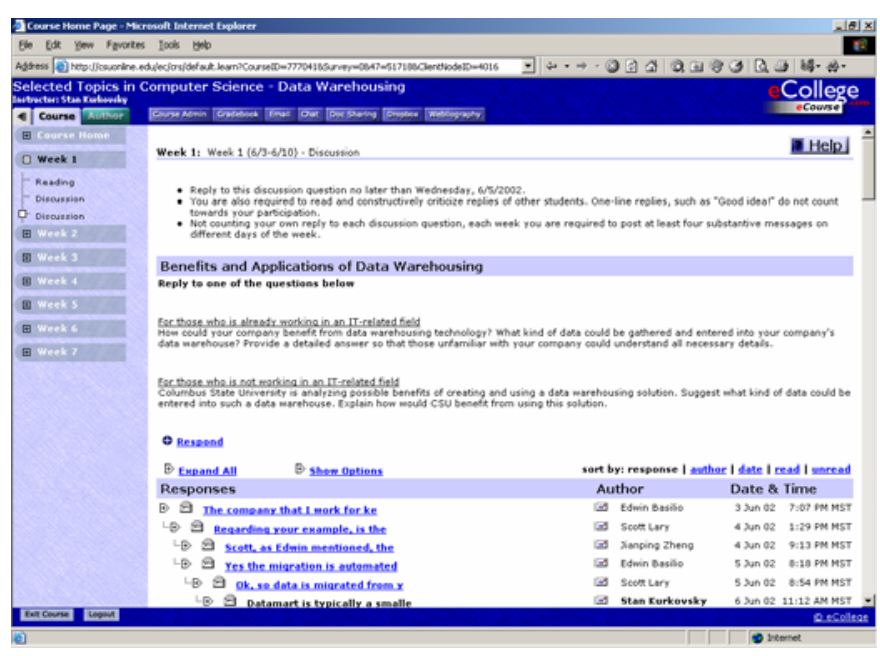

Figure 1. eCollege Environment for Online Courses

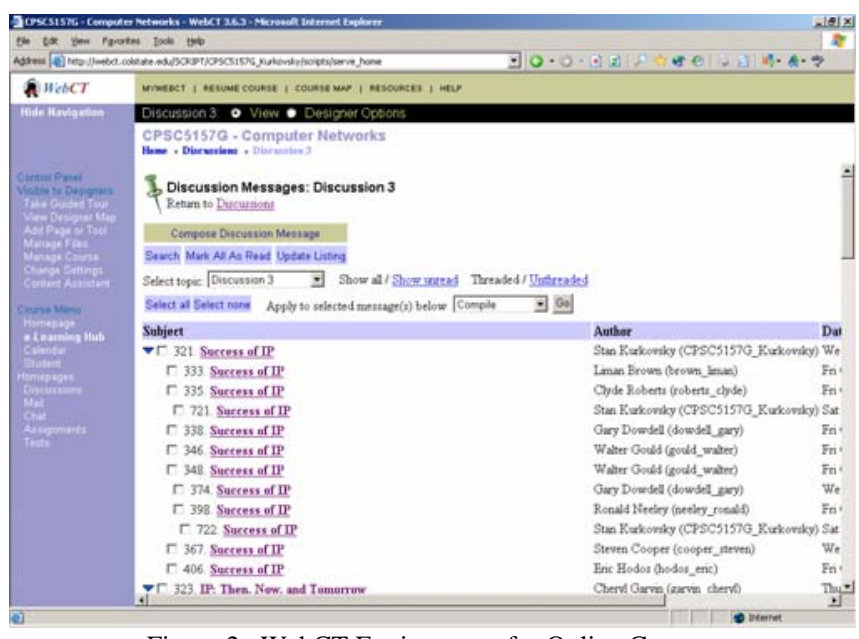

Figure 2. WebCT Environment for Online Courses

As a way to break the ice in online discussions and to help students get to know each other better, they were asked to post their informal biographies during the first week of the course. All discussion questions offered in this course and presented in Table I are building on the course textbook material, students' hands-on exercises and on the experience of the previous material.

Student feedback collected at the end of this course appears to validate our claim of the effective use of online asynchronous discussions in our graduate program. Below is a brief sampling of the comments students wrote upon the completion of this course:

- Online discussions are a great tool and were what I had hoped for. Most other students' inputs were productive and helped in learning.

- $\quad$ The discussion board was a great idea. It was a way a student could have a question answered by both the instructor and the class, similar to raising your hand in a classroom.

- I thought the online discussions were a good idea. It gave everyone a chance to express their opinion about topics. I think this is great, because everyone's voice in the class is heard.

In this course, we used eCollege [2] as the technology to support online classroom management. Web-based environment of eCollege offers an easy and intuitive way to support threaded discussions, as demonstrated in Figure 1. In the Fall semester of 2003, we switched to WebCT [8], which provides an equivalent set of features needed for a successful support of an online course as shown in Figure 2.

\section{CONCLUSIONS}

In this paper we presented a collective experience of faculty teaching online graduate computer science courses at Columbus State University. Asynchronous discussions are an integral part of every online course that we teach. We believe that these discussions can not only replace the traditional classroom experience, but they can also make this experience much richer. When applied and managed properly, asynchronous discussions can give many opportunities to all students to actively and productively participate in the learning process. Here we presented some observations that worked in our setting. We hope the readers will find them helpful and beneficial to their online courses.

\section{REFERENCES}

[1] S. Blignaut, S. Trollip, "Developing a Taxonomy of Faculty Participation in Asynchronous Learning Environments: an Exploratory Investigation,” Computers and Education, Vol. 41 No. 2, 149-172, Elsevier, September 2003.

[2] eCollege, http://www.ecollege.com.

[3] R. Frazee. "Using Relevance to Facilitate Online Participation in a Hybrid Course,” Educause Quarterly, No. 4, 2003, 67-69.

[4] S. Kurkovsky, "Graduate Computer Science Courses: Facilitating Online Discussions,” in Proceedings of The 2002 ACM Mid Southeast Chapter Fall Conference, Gatlinburg, TN, November 2002.

[5] K. Meyer, "Face-To-Face Versus Threaded Discussions: The Role of Time and Higher-Order Thinking," Journal of Asynchronous Learning Networks, Vol. 7, No. 3, September 2003, 55-65.

[6] B. Murray. "Reinventing Class Discussion Online," Monitor on Psychology, April 2000, 31, 54-56.

[7] D. Raleigh, "Keys to Facilitating Successful Online Discussions," Teaching with Technology Today, Vol. 7, No. 3, November 15, 2000, http://www.uwsa.edu/ttt/raleigh.htm.

[8] WebCT, http://www.webct.com.

[9] D. Wu, S. Hiltz, "Online Discussions and Perceived Learning," in Proceedings of The $9^{\text {th }}$ Americas Conference on Information Systems, August 2003, Tampa, FL, 687-696. 